\title{
OPEN Numerical analysis of photonic crystal fiber of ultra-high birefringence and high nonlinearity
}

\author{
Patrick Atsu Agbemabiese ${ }^{\bowtie}$ \& Emmanuel Kofi Akowuah
}

A numerical analysis of a hexagonal PCF structure with four circular air hole rings around the core has been presented in this paper. By utilizing a full vectorial finite element method with perfectly matched layers, propagation properties such as birefringence, chromatic dispersion and confinement losses are numericaly evaluated for the proposed PCF structure. Specifically, birefringence of $2.018 \times 10^{-2}$, nonlinear coefficients of $40.682 \mathrm{~W}^{-1} \mathrm{~km}^{-1}$, negative chromatic dispersion of $-47.72 \mathrm{ps} / \mathrm{km} . \mathrm{nm}$ at $1.55 \mu \mathrm{m}$ and -21 to $-105 \mathrm{ps} / \mathrm{km} . \mathrm{nm}$ at the telecommunication band of $\mathrm{C}-\mathrm{U}$ have been reported.

Photonic crystal fibers (PCFs) have outperformed its conventional step index fiber counterpart. This is due to the flexibility in the design of the structure, the material used and application. PCFs referred to as microstructures or holey fibers have received growing interest in recent years. They are classified into two categories according to its light guiding mechanism; photonic band gap guiding and refractive index guiding which is based on total internal reflection. Both band gap and index guiding PCFs have claddings which consist of air holes, although they differ in the structure of the core $e^{1,2}$. In Solid core PCfs, the refractive index contrast is achieved by the arrangement of air holes in the cladding ${ }^{3}$. PCFs have a range of degrees of freedom and design flexibility to control optical properties such as endless single mode ${ }^{4}$, high birefringence ${ }^{5}$, chromatic dispersion management ${ }^{6}$, large mode area $^{7}$, high nonlinearity ${ }^{8}$ and low confinement loss ${ }^{9}$. These properties open the door for a lot of applications like; nonlinear optics ${ }^{10}$, sensing ${ }^{1}$, high power technology $y^{11}$ and telecommunications ${ }^{12,13}$. The optical properties can be achieved through optimisation of air hole shape, size and position ${ }^{14-17}$.

Birefringence is generally categorized into two; these are geometrical birefringence and stress birefringence ${ }^{18,19}$. Optical fibers are doped in order to increase the refractive index, change the melting properties and induce birefringence $^{1}$. High Birefringence is required to keep two linear orthogonal polarisation states over long distance. High birefringent PCFs are highly sensitive to temperature, a characteristic which is important in sensing applications ${ }^{20}$.

Dispersion is a measure of the temporal broadening of the optical pulse and it is one of the main sources of penalty for efficient transmission of optical signals. A PCF of high Birefringence and negative dispersion compensation is important in optical amplification as it maintains linear polarisation and useful for double Raman gains and sensing ${ }^{21}$. Furthermore, research has shown that achieving high birefringence, high nonlinearity and negative dispersion can be useful for polarization control in fiber optic sensors, telecommunication applications and broadband dispersion compensation in high-bit-rate transmission systems ${ }^{22}$. A lot of work has been reported recently to achieve high birefringence, high nonlinearity and dispersion management through the use of elliptical holes around the core ${ }^{23,24}$, using different shapes of air holes other than circular in or around the $\operatorname{core}^{25-27}$, defective core ${ }^{21}$, doping the core with gas or liquid and hybrid cladding ${ }^{28,29}$, double cladding ${ }^{22}$, dual core photonic bandgap ${ }^{30}$, triangular lattice ${ }^{31}$ and other shapes of air hole rings apart from the widely used hexagonal lattice ${ }^{32-35}$. Rhombic and elliptical hole PCFs have been presented ${ }^{26}$ to achieve birefringence (B) of $8 \times 10^{-3}$ and Confinement loss $(\mathrm{CL})$ of $5 \times 10^{-4} \mathrm{~dB} / \mathrm{m}$ at $1.55 \mu \mathrm{m}$. However chromatic dispersion, which plays a key role in optical communication was not reported on by ${ }^{26}$. Furthermore, fabrication of such structures are relatively difficult considering the complex designs rhombic desings present ${ }^{26}$. There are also reports of PCF structures combining circular and elliptical holes to achieve ${ }^{36} \mathrm{~B}$ of $10^{-3}$ and a CL of $10^{-7} \mathrm{~dB} / \mathrm{m}$. Despite the impressive performance of the structures presented $b^{36}$, the chromatic dispersion properties are not presented by the authors ${ }^{36}$. Similar to the strutctures presented by ${ }^{26}$, these structures are bulky, complex and ccostly to fabricate ${ }^{36}$.

There is a growing interest in hybrid PCF structures which employ two or more lattice structures. One such example is presented by ${ }^{28}$, which consists of hexagonal and decagonal structures with five air hole rings. The structure reported CL of $8.13 \times 10^{-3} \mathrm{~dB} / \mathrm{m}$ and $\mathrm{B}$ of $2.6 \times 10^{-2}$ with a very high negative compensation at $1.55 \mu \mathrm{m}$, which is similar to ${ }^{37}$. In the PCF structure by ${ }^{5,38}$ a very high $\mathrm{B}$ of $10^{-3}$ at a low CL have was reported but elliptical 


\begin{tabular}{|l|l|}
\hline Parameters & Constants \\
\hline B1 & 0.69675 \\
\hline B2 & 0.408218 \\
\hline B3 & 0.890815 \\
\hline C1 & $4.67914826 \mathrm{e}-3$ \\
\hline C2 & $1.35120631 \mathrm{e}-2$ \\
\hline C3 & 97.9340025 \\
\hline
\end{tabular}

Table 1. Values of sellmeier coefficients for background silica material.

air holes incorporated in the core of the structures make fabrication difficult. A design with seven rectangular air holes located in the core has been presented in ${ }^{27}$ with very low loss. However the fabrication of rectangular holes would be difficult. Paul et al. ${ }^{23}$, designed a PCF of square lattice with five air hole rings made up of both circular and elliptical air holes. A very high value of dispersion compensation (DC) and a high B of $4.74 \times 10^{-3}$ has been achieved however, owing to the number of elliptical holes present in the design, the fabrication of the structure would be difficult.

Another high B in the order of $10^{-2}$ and very large negative dispersion is presented in $^{24,39,40}$ but, the structure contains elliptical holes around the core which increases fabrication difficulty. A dual concentrated core with five layer air hole ring has been presented with high DC and low CL of $10^{-4} \mathrm{~dB} / \mathrm{m}$ but no birefringence results were shown. $\mathrm{In}^{21}$, seven rings of square lattice structure of circular air holes was proposed. A high B of the order of $10^{-2}$ was obtained with negative chromatic dispersion. Furthermore, Arif et al. ${ }^{5}$ demonstrated a nonlinearity of $39.330 \mathrm{~W}^{-1} \mathrm{~km}^{-1}$ but with a low B of $2.83 \times 10^{-3}$. In ${ }^{22}$, high B of $3.12 \times 10^{-2}$, nonlinearity of $24.89 \mathrm{~W}^{-1} \mathrm{~km}^{-1}$ and high negative dispersion has been proposed however the nonlinearity is low and the structure is complex and fabrication would be a challenge. It has also been demonstrated in ${ }^{41}$ that nonlinearity of $26.67 \mathrm{~W}^{-1} \mathrm{~km}^{-1}$ can be achieved at a pump wavelength of $1.3 \mu \mathrm{m}$. Bored core PCF reported in ${ }^{42}$, achieved a nonlinearity of $118.4 \mathrm{~W}^{-1} \mathrm{~km}^{-1}$ and a negative dispersion value of $-2221 \mathrm{ps} / \mathrm{km} . \mathrm{nm}$ but the birefringence (B) was not discussed.

It is clear from the aforementioned research works that it is very difficult to simultaneously achieve excellent birefringence, chromatic dispersion and nonlinear coefficient for a given PCF structure. This paper presents a proposed PCF structure with ultra-high B of $2.018 \times 10^{-2}$ and nonlinear coefficients of $40.72 \mathrm{w}^{-1} \mathrm{~km}^{-1}$ at $1.55 \mu \mathrm{m}$. Chromatic dispersion of $-47.7 \mathrm{ps} / \mathrm{km} . \mathrm{nm}$ at $1.55 \mu \mathrm{m}$ has been demonstrated.

Our proposed PCF structure with high B and high nonlinearity within optical communication wavelengths is very desirable in high bit rate data communication, polarization maintaining and sensing applications.

\section{Design methodology}

Refractive index of pure silica is dependent on the wavelength, and for this structure, SellMeier equation ${ }^{43}$ used: $^{2}$

$$
n^{2}=1+\frac{\mathrm{B}_{1} \lambda^{2}}{\lambda^{2}-c_{1}}+\frac{\mathrm{B}_{2} \lambda^{2}}{\lambda^{2}-c_{2}}+\frac{\mathrm{B}_{3} \lambda^{2}}{\lambda^{2}-c_{3}}
$$

where $\mathrm{n}$ is the refractive index of the silica and $\lambda$ is the wavelength in $\mu \mathrm{m} . \mathrm{B}_{1,2,3}$ and $\mathrm{C}_{1,2,3}$ are SellMeier coefficients as shown in Table 1.

In this paper in order to determine the optical properties of the PCF the cross section is segregated into subspaces where Maxwell equation are computed by determining the adjacent subspaces. The vectorial Eq. (2) is determined using anisotropic $\mathrm{PML}^{14,44}$ :

$$
\nabla \times\left(\left[S^{-1}\right] \nabla \times E\right)-k_{0}^{2} n^{2}[S] E=0
$$

where $\mathrm{ko}=2 \pi / \lambda$ is the wave number in vacuum, $\lambda$ is the wavelength, $\mathrm{E}$ is the electric field vector, $\mathrm{n}$ is the refractive index of the domain, $[\mathrm{s}]$ is the PML matrix, $[\mathrm{s}]^{-1}$ is an inverse matrix of $[\mathrm{s}]$.

Dispersion is a key factor that reduces the information that the fiber cable can carry. The presence of dispersion results in the spreading of the pulse creating intersymbol interference. Dispersion can categorised into two ,that is intermodal and intramodal dispersion. Intermodal occurs in multimode fibers while intermodal occurs in single mode fibers. Dispersion is made up of the material dispersion and waveguide dispersion The chromatic dispersion is calculated with the formula ${ }^{1}$;

$$
D=-\frac{\lambda}{c} \frac{\partial^{2} \operatorname{Re}\left(n_{e f f}\right)}{\partial \lambda^{2}}
$$

where $c$, is the speed of light in free space and Re is the real value of the effective refractive index.

Birefringence $(B)$ is the difference in the refractive indices of the two polarisation modes. It is calculated $\mathrm{as}^{45}$;

$$
B=\left|n_{x}-n_{y}\right|
$$

where $n_{x}$ and $n_{y}$ are the effective refractive indices for $x$ and $y$ polarization modes respectively.

The confinement loss is calculated from the imaginary part of the effective refractive index. 
In PCFs the light propating through the core is due to the finite rings of air holes in the bulk silica which extends to infinity. Leakage of light from the core to the exterior matrix is unavoidable even though the jacket is far from the cladding and core region. This leakage of light causes confinement loses. The formula that is used to compute confinement loss is given by ${ }^{44}$

$$
C_{\text {loss }}=\frac{40 \pi}{\ln (10) \lambda} \operatorname{Im}\left(n_{\text {eff }}\right)\left[\frac{d B}{m}\right]
$$

where $\lambda$ is the operating wavelength. $I_{m}\left(n_{e f f}\right)$ is the imaginary value of the effective refractive index.

The effective mode area is a parameter which determines the performance of the PCF and it is given by ${ }^{14}$ :

$$
A_{\text {eff }}=\frac{\left(\iint|E|^{2} d x d y\right)^{2}}{\iint|E|^{4} d x d y}
$$

where $\mathrm{E}$ is the amplitude of the transverse electric field.

Non-linear coefficient $(\gamma)$ determined in the core of the fiber is given by:

$$
\gamma=\frac{2 \pi}{\lambda} \frac{n_{2}}{A_{e f f}}
$$

where $\mathrm{n}_{2}$ is the refractive index coefficient and for this work $2.76 \times 10^{-20} \mathrm{~m}^{2} / \mathrm{W}$ is used.

Beat length is calculated using;

$$
L_{B}=\frac{\lambda}{\left|n_{x}-n_{y}\right|}=\frac{\lambda}{B}
$$

\section{Simulation and results}

The proposed paper seeks to design and optimise a PCF structure that demonstrates high birefringence, negative chromatic dispersion and high nonlinearity. Four structures PCF1, PCF2, PCF3 and PCF4 which are all hexagonal with four air hole rings are presented in Figs. 1 to 4 respectively. Comsol multiphysics is used for the entire simulation. Simulation has been done in the range of wavelength of $0.7 \mu \mathrm{m}$ to $2 \mu \mathrm{m}$.

PCF1 has been designed with air holes whose diameters increase along the main diagonal axis. The hole to hole spacing, $\Lambda$ is kept at $1.7 \mu \mathrm{m}$ with an air filling fraction, $\mathrm{d} / \Lambda$ fixed at 0.6 . The air hole diameter $(\mathrm{d})=1.02 \mu \mathrm{m}$ .The descending air holes from the outer ring to the inner air hole ring have been designed to follow the following pattern; $\mathrm{d}_{1}=0.25 \mathrm{~d}, \mathrm{~d}_{2}=0.75 \mathrm{~d}, \mathrm{~d}_{3}=\mathrm{d}$ and $\mathrm{d}_{4}=1.25 \mathrm{~d}$. The descending hole design is chosen due to its high nonlinearity and also most of the designs that is known to us did not consider it. The Perfectly matched layer (PML) has been designed with thickness of $\mathrm{W}=2 \mu \mathrm{m}, \mathrm{wx}=20.6 \mu \mathrm{m}$ and $w y=24 \mu \mathrm{m}$. PCF1 is shown in Fig. 1a.

Figure 1b, shows PCF2 structure where the air hole sizes at the two orthogonal axes have been altered by arranging them in an ascending order in terms of diameter, whilst those at the inner ring are kept at $\mathrm{d}_{4}=1.25 \mathrm{~d}$. The hole to hole spacing and air filling fraction are the same as that of PCF1.This PFC2 has been done to alter the symmetry of the structure in order to improve the birefringence.

In the case of PCF3 as shown in Fig. 1c, the birefringence is improved by two Elliptical holes E, of a-semi axes of $0.765 \mu \mathrm{m}$ and $\mathrm{b}$-semi axes of $1.53 \mu \mathrm{m}$ which have been introduced into the inner ring. The other two air holes in the inner ring have been reduced to $\mathrm{d}_{1}=0.25$ but the last two remained as in PCF1. The pitch is varied in the order of $1.7 \mu \mathrm{m}, 1.8 \mu \mathrm{m}, 1.9 \mu \mathrm{m}$ and $2.3 \mu \mathrm{m}$ in order to determine the effect of the pitch on the optical properties in PCF3.

In PCF4, the elliptical holes have been replaced with circular ones. These two air holes are of diameter $\mathrm{d}_{4}$ whilst the rest are kept the same as in PCF3. However, the hole to hole spacing between the first and second ring is changed from $\Lambda=1.7$ to $\Lambda=1.4$. The full structure is shown in Fig. 1d.

The Fig. 2, shows the field profile of fundamental mode for all the PCF structures. The modal field distribution of the fundamental mode shows a well confined light in the core for PCF1,PCF2, PCF3 and some small leakage in PCF4. Comsol multiphysics is used for the simulation. Simulation has been done in the wavelength range of $0.7 \mu \mathrm{m}$ to $2 \mu \mathrm{m}$.

\section{Results and discussion}

This section investigates the effects of structural parameters such as pitch, hole sizes and air filling fraction on the performance parameters of the proposed PCF structures. Of specific interest are performance parameters such as birefringence, confinemet loss, chromatic dispersion and nonlinearity.

The effect of Change of hole sizes in the two orthogonal axes. The effective refractive index decreases as the wavelength increase for x-polarisation as shown in Fig. 3 for PCF1 and PCF2. The graph indicates an insignificant change in the effective refractive index values of PCF1 and PCF2 which shows that the change in hole sizes at the two orthogonal axes do not significantly affect the effective refractive index.

A critical examination of the CD values reveal that they did not change as shown in Fig. 4 of PCF1 and PCF2 since the real effective index value determines the $\mathrm{CD}$. This $\mathrm{CD}$ values agrees with the ascertion in ${ }^{16}$ that dispersion is affected by the holes in the inner ring since the field is propagated in the core.

At $1.55 \mu \mathrm{m}$ the B value in Fig. 5 for PCF1 is $2.241 \times 10^{-6}$ and that of PCF2 is $2.022 \times 10^{-6}$ which demonstrates that change in hole sizes at the two orthogonal axes of PCF2 did not affect B. 

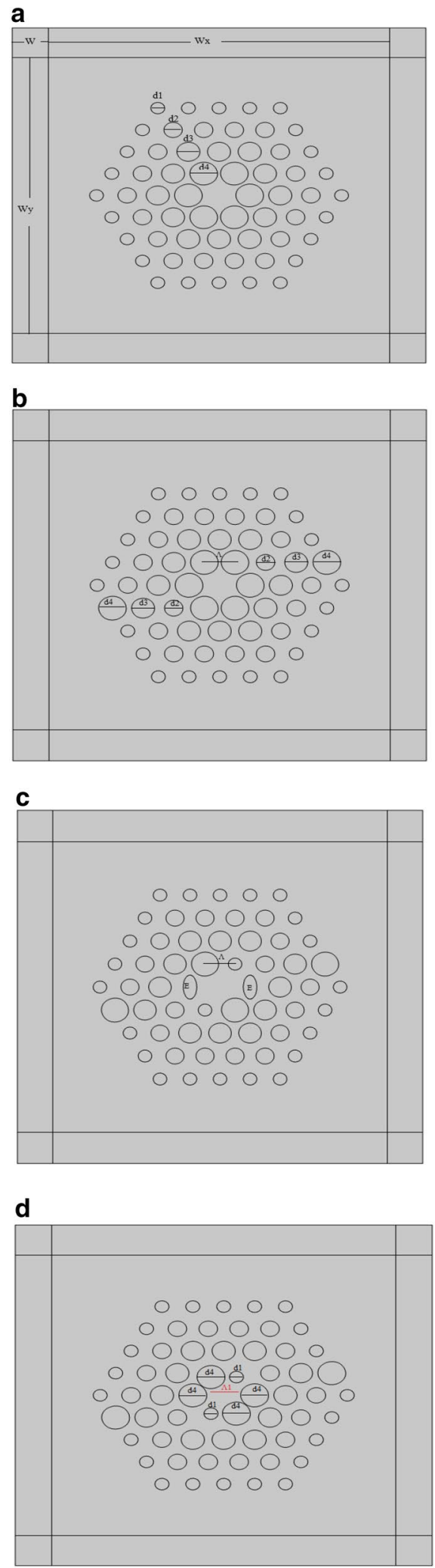

Figure 1. (a) PCF Structure, PCF 1. (b) PCF Structure, PCF 2. (c). PCF Structure, PCF 3. (d) PCF Structure, PCF 4. 


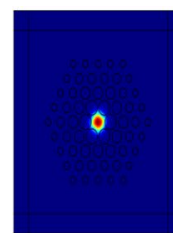

(x1)

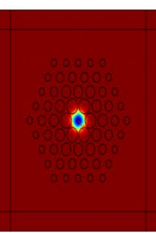

(y1)

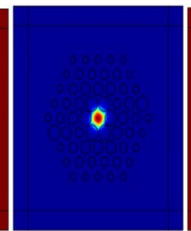

(x2)

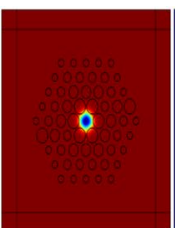

(y2)

(x3)

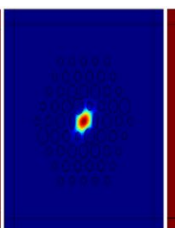

(y3)

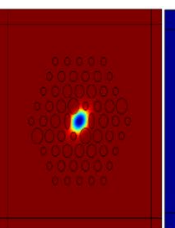

(x4)

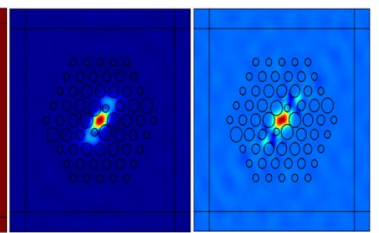

(y4)

Figure 2. The fundamental mode field profile of $x$-polarisation and y-polarisation at $1.55 \mu \mathrm{m}$ for; PCF1, PCF2, PCF3, PCF4 respectively.

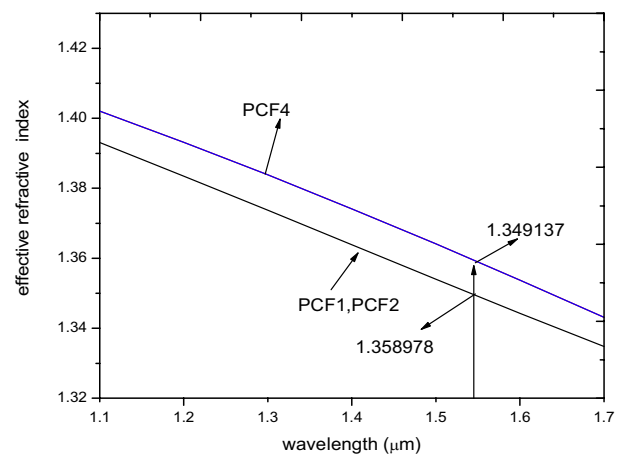

Figure 3. Effective refractive index of $x$-polarisation against wavelength for PCF1, PCF2, PCF3 and PCF4.

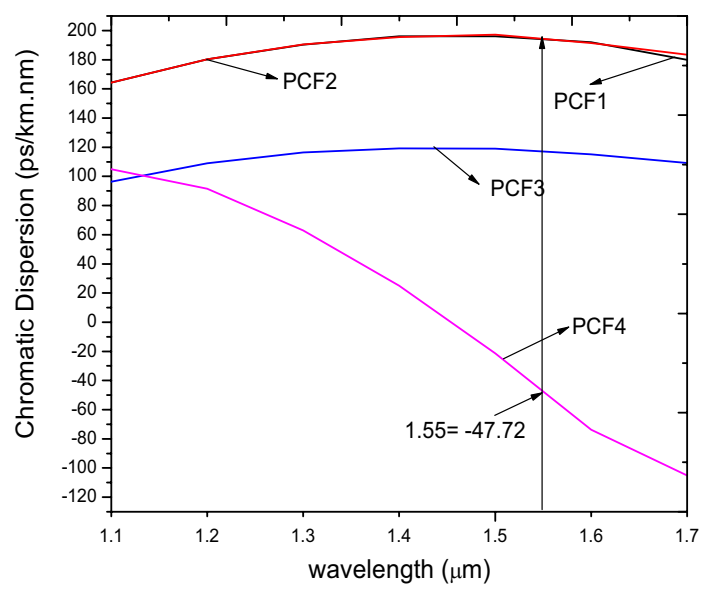

Figure 4. Chromatic dispersion of $x$-polarisation mode against wavelength for PCF1, PCF2, PCF3 and PCF4.

The values of CL in Fig. 6 for PCF1 and PCF2 are $0.12654 \mathrm{~dB} / \mathrm{m}$ and $0.104607 \mathrm{~dB} / \mathrm{m}$ which is an indication of small reduction in leakage of light at the core in PCF1 as compared to PCF 2.

The nonlinear coefficients in Fig. 7 for PCF1 and PCF2 are $52.445 \mathrm{~W}^{-1} \mathrm{~km}^{-1}$ and $52.446 \mathrm{~W}^{-1} \mathrm{~km}^{-1}$ respectively at $1.55 \mu \mathrm{m}$ which indicates that the descending hole arrangement give rise to a very high nonlinearity.

The effect of structural parameters of air holes in PCF 3. This section looks at the performance parameters of PCF3, which involves the introduction of elliptical air holes and the modification of $d_{4}$ to $d_{1}$. The introduction of elliptical air holes in the inner ring around the core in PCF3 increased the birefringence from $10^{-6}$ in Fig. 5 to $10^{-3}$ shown in Fig. 8, which is in agreement with work reported $\mathrm{in}^{34,46}$. However, The nonlinearity in Fig. 7, decreased from 52.445 $\mathrm{W}^{-1} \mathrm{~km}^{-1}$ for PCF 1 and PCF 2 to $31.32 \mathrm{~W}^{-1} \mathrm{~km}^{-1}$ for PCF 3 at $1.55 \mu \mathrm{m}$.

The CD as seen in Fig. 4, shows that both PCF1 and PCF2 possess flat profiles but that of PCF3 is relatively lower than both of them across the entire wavelength range.

The CL of PCF3 saw a steady decline to $0.04823 \mathrm{~dB} / \mathrm{m}$ at $1.55 \mu \mathrm{m}$, which indicates a relatively better confinement of light in the core, compared to both PCF1 and PCF2 as shown in Fig. 6. Nonetheless, the change in the hole sizes at the orthogonal axes in PCF2 did not affect the CL and nonlinearity. 


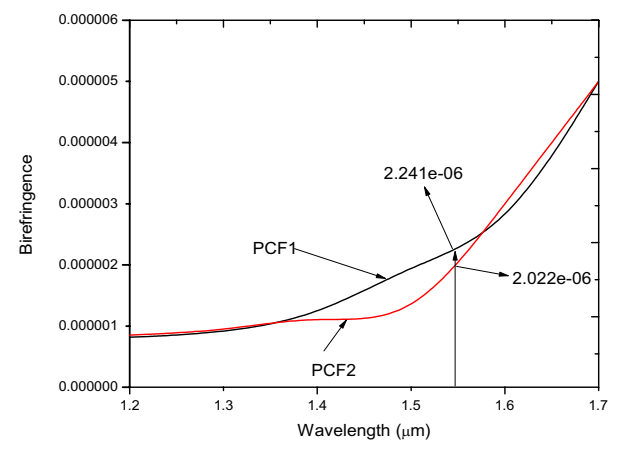

Figure 5. Birefringence against wavelength for PCF1, PCF2.

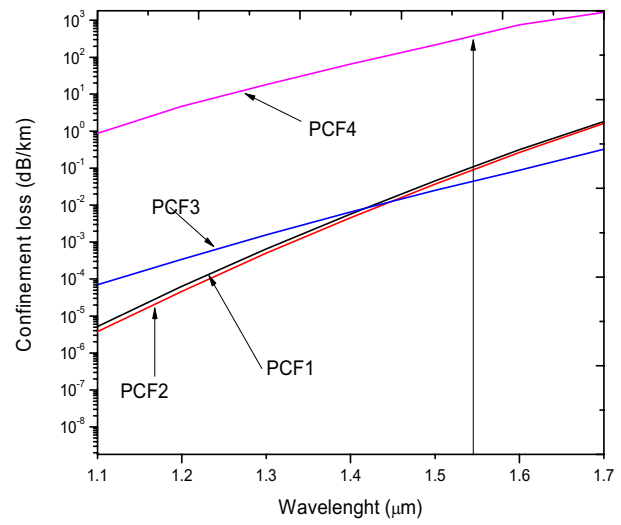

Figure 6. Confinement loss of $\mathrm{x}$-polarisation against wavelength for PCF1, PCF2, PCF3 and PCF4.

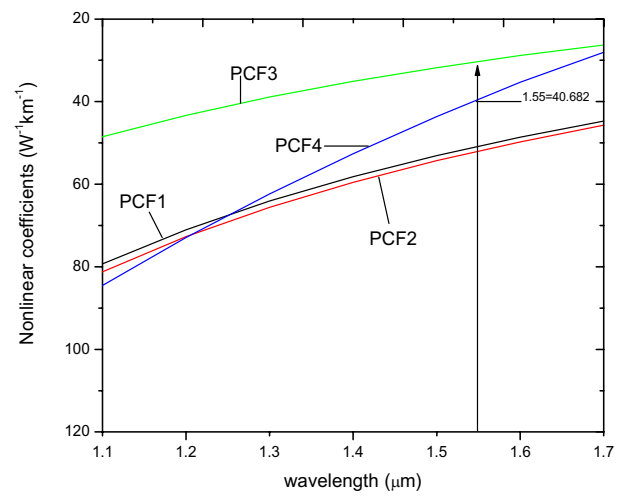

Figure 7. Nonlinear coefficients of $\mathrm{x}$-polarisation against wavelength for PCF1, PCF2, PCF3 and PCF4.

Effect of Variation of the pitch in PCF3. Figure 9 shows a general decrease in the real effective refractive index as the wavelength increases for x polarisation. It can also be observed that as the hole to hole spacing (pitch) increases, the effective refractive index increase. The $\Lambda=2.3 \mu \mathrm{m}$ shows the highest values of the real effective index while that of $\Lambda=1.7 \mu \mathrm{m}$ indicates the lowest value. At $1.55 \mu \mathrm{m}$, the real effective index for $\Lambda=1.7 \mu \mathrm{m}$, $\Lambda=1.8 \mu \mathrm{m}, \Lambda=1.9 \mu \mathrm{m}, \Lambda=2.3 \mu \mathrm{m}$ are $1.3896,1.3951,1.3986$ and 1.4112 for x-polarisation.

The birefringence analysis shown in Fig. 10, shows that the highest value of birefringence recorded at $1.55 \mu \mathrm{m}$ for the hole to hole spacing of $1.7 \mu \mathrm{m}$ is 0.003838 which is in agreement with ${ }^{26,38,47-49}$ and close to ${ }^{37,50}$. The birefringence obtained for all pitch values are in the order of $10^{-3}$, which spans over a wavelength range of $\mathrm{O}$ to U optical communication bands.

Figure 11, indicates the relationship between the beat length and the wavelength. The plot shows that an in increase in $\Lambda$ results in an increase in the the beat length. 


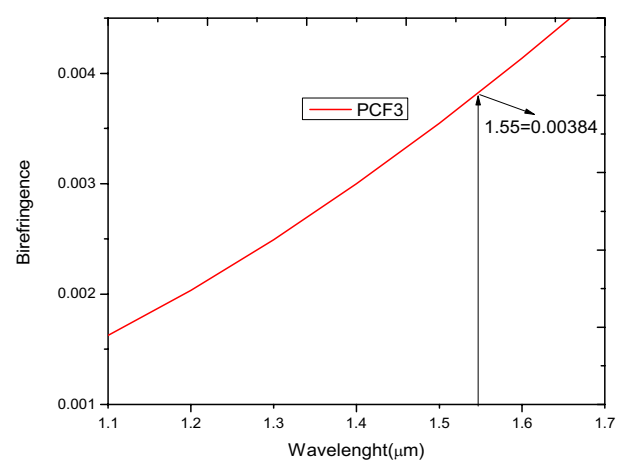

Figure 8. Birefringence against wavelength for PCF3.

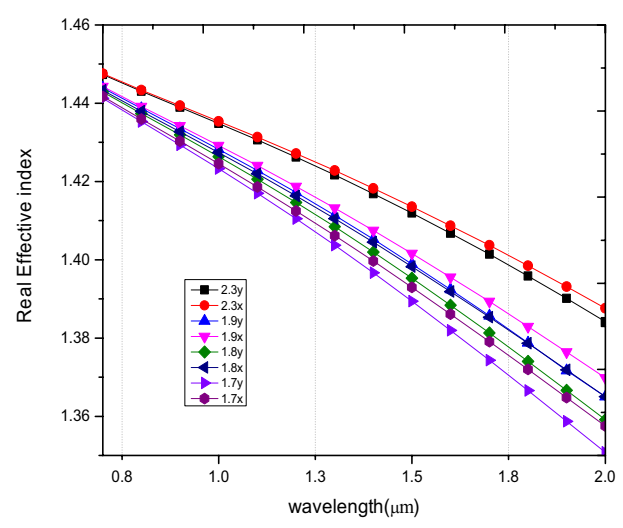

Figure 9. Variation of wavelength against real effective index, PCF3 for $\Lambda=1.7 \mu \mathrm{m}, 1.8 \mu \mathrm{m}, 1.9 \mu \mathrm{m}, 2.3 \mu \mathrm{m}$ for $\mathrm{x}$ and y polarisation.

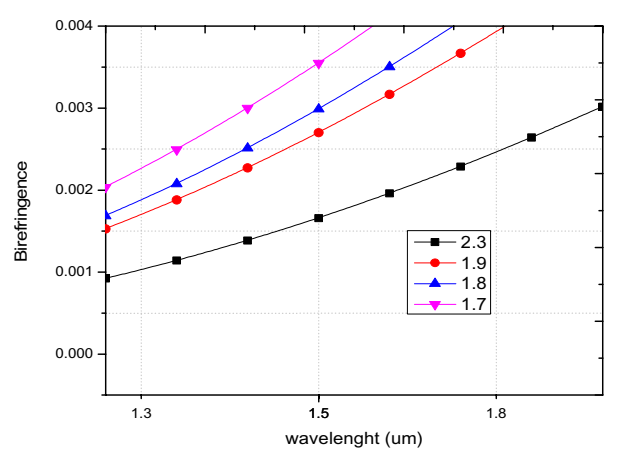

Figure 10. Variation of wavelength against birefringence for PCF3 at $\Lambda=1.7 \mu \mathrm{m}, 1.8 \mu \mathrm{m}, 1.9 \mu \mathrm{m}, 2.3 \mu \mathrm{m}$, $\mathrm{d} / \Lambda=0.6$.

Another performance parameter which is highly dependent on the pitch is the nonlinear coefficient. This is confirmend in Fig. 12, where it shown to be inversely propotional to the pitch and wavelength. Specifically, it is shown that a value of $31.3 \mathrm{w}^{-1} \mathrm{~km}^{-1}$ is obtained at a wavelength of $1.55 \mu \mathrm{m}$, for a pitch of $1.7 \mu \mathrm{m}$ at $\mathrm{x}$-polarization mode, whilst that for a pitch of $2.3 \mu \mathrm{m}$ reduces to $19.158 \mathrm{w}^{-1} \mathrm{~km}^{-1}$ the same wavelength.

Results from the analysis of the effective mode area which is shown in Fig. 13, shows that the effective mode area increases gradually with increase in wavelength. In relation to the pitch, the effective area increases with increase in pitch with the highest value at a pitch of $2.3 \mu \mathrm{m}$. The effective mode area at $1.55 \mu \mathrm{m}$ for $\Lambda=1.7$ is $3.69 \mu \mathrm{m}^{2}$ for $\mathrm{x}$-polarization mode which is close to ${ }^{51}$ with $\mathrm{d} / \Lambda=0.6$. These results indicate that unlike the nonlinear coefficient, the effective mode area is directly proportional to the pitch and wavelength.

In Fig. 14, CL decreases with increase in hole to hole spacing. The pitch, $2.3 \mu \mathrm{m}$ at $1.55 \mu \mathrm{m}$ indicates a confinement loss of $9.67 \times 10^{-5} \mathrm{~dB} / \mathrm{m}$ and $1.0034 \times 10^{-4}$ for $\mathrm{x}$ and y polarization mode respectively which is lower 


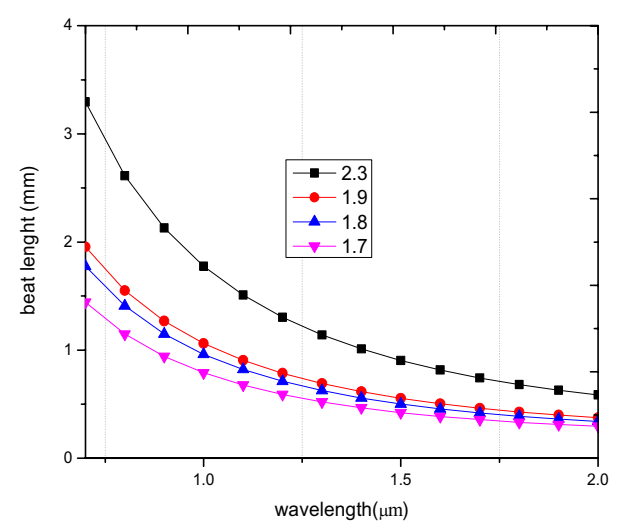

Figure 11. Variation of wavelength against beat length for PCF3 at $\Lambda=1.7 \mu \mathrm{m}, 1.8 \mu \mathrm{m}, 1.9 \mu \mathrm{m}, 2.3 \mu \mathrm{m}, \mathrm{d} / \Lambda=0.6$.

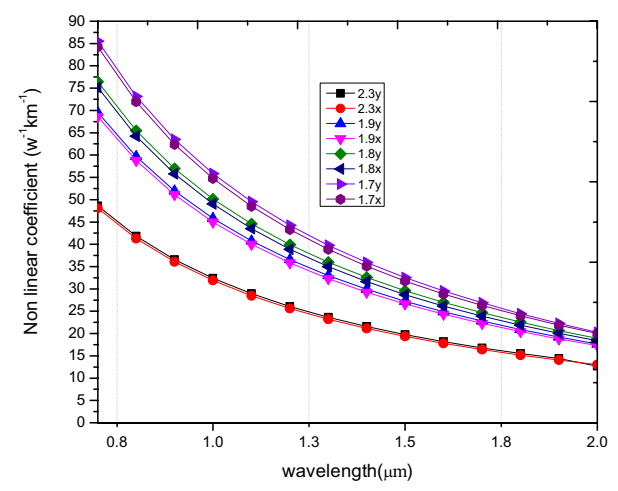

Figure 12. Variation of wavelength against nonlinear coefficient of PCF3 at $\Lambda=1.7 \mu \mathrm{m}, 1.8 \mu \mathrm{m}, 1.9 \mu \mathrm{m}, 2.3 \mu \mathrm{m}$, $\mathrm{d} / \Lambda=0.6$.

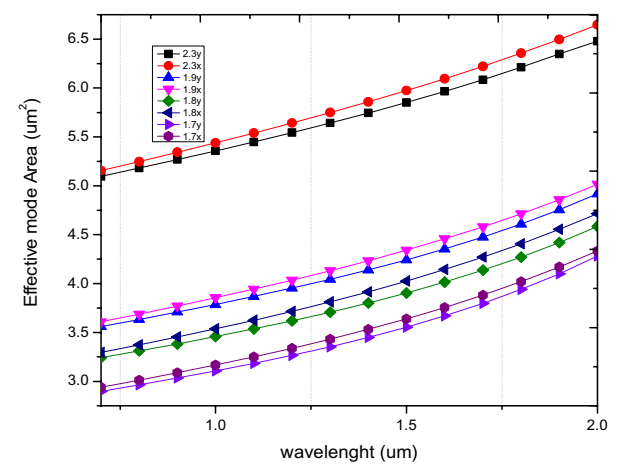

Figure 13. Variation of wavelength with effective mode area for $\Lambda=1.7 \mu \mathrm{m}, 1.8 \mu \mathrm{m}, 1.9 \mu \mathrm{m}, 2.3 \mu \mathrm{m}, \mathrm{d} / \Lambda=0.6$.

than ${ }^{26,37,52}$. The CL value shows that confinement loss can be improved by increasing the hole to hole spacing for a given air hole filling fraction.

The CD decreases as the pitch increases as shown in Fig. 15. Zero CD has been obtained for all the pitch values at a wavelength range of $0.9 \mu \mathrm{m}$ to $1.1 \mu \mathrm{m}$ similar to ${ }^{53}$. Positive dispersion is obtained for all the $\Lambda$ at $1.55 \mu \mathrm{m}$ between 100 to $126 \mathrm{ps} / \mathrm{nm} / \mathrm{km}$.

Performance characteristics of PCF4. The performance analysis presented on PCF 1-3 indicate the relative strengths and weaknesses of the respective structures. It gives an indication of the optimisation process, starting with PCF1 as the base structure and gruadually evolving it towards the optimised structure based on our desired performance parameters. 


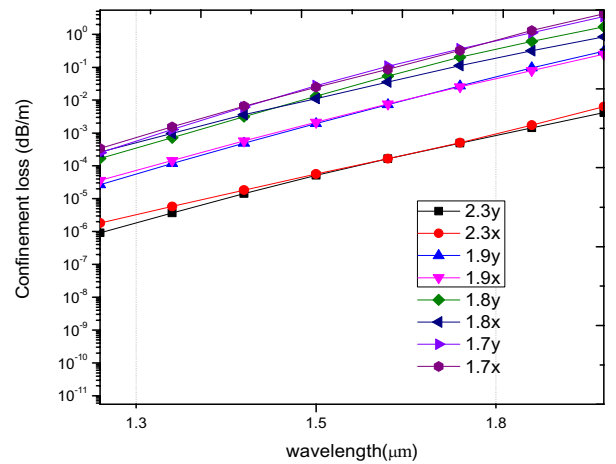

Figure 14. Variation of wavelength with confinement loss for $\Lambda=1.7 \mu \mathrm{m}, 1.8 \mu \mathrm{m}, 1.9 \mu \mathrm{m}, 2.3 \mu \mathrm{m}, \mathrm{d} / \Lambda=0.6$.

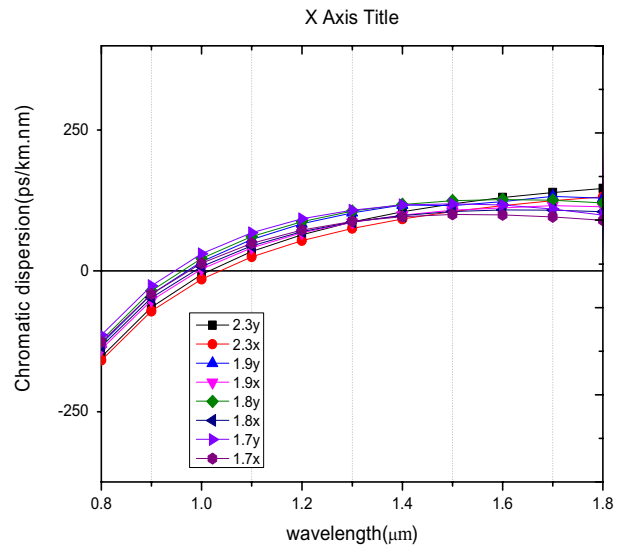

Figure 15. Variation of wavelength with chromatic dispersion (a) for $\Lambda=1.7 \mu \mathrm{m}, 1.8 \mu \mathrm{m}, 1.9 \mu \mathrm{m}, 2.3 \mu \mathrm{m}$, $\mathrm{d} / \Lambda=0.6$.

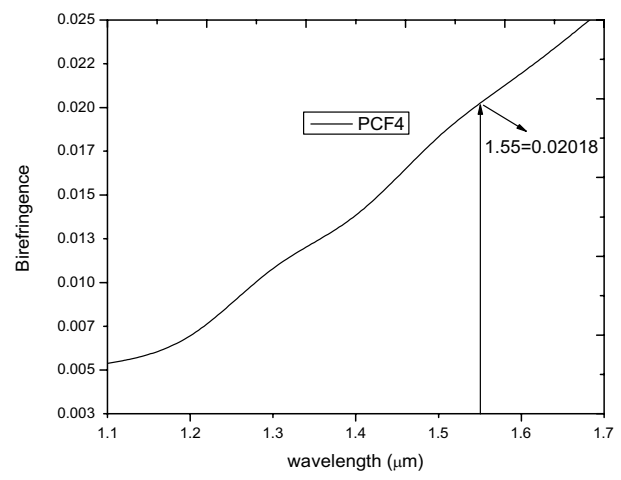

Figure 16. Birefringence against wavelength PCF4.

In this regard, a new structure called PCF4 as shown in Fig. 1d is derived from PCF 1-3. Comparing Fig. 8 to 16 shows that the B increases from 0.003838 in the case of PCF3 to 0.0202 for PCF4 at the same wavelength of $1.55 \mu \mathrm{m}$. This is higher that those reported in ${ }^{5,26,38}$ and comparable to ${ }^{22,54}$. The birefringence shown in Fig. 16, is in the order of $10^{-2}$ which covers the wavelength range from $1.3 \mu \mathrm{m}$ to $1.7 \mu \mathrm{m}$. In conventional polarisation fibers it is reported that the modal birefringence is $5 \times 10^{-4} 28$ which is far lower than the B of both structures PCF3 and PCF4. The ultra-high birefringence achieved can be useful for applications in sensing and signal processing.

On the issue of nonlinearity, Fig. 7 shows that of PCF4 is $40.68 \mathrm{~W}^{-1} \mathrm{~km}^{-1}$, which is higher than $31.32 \mathrm{~W}^{-1} \mathrm{~km}^{-1}$ for PCF3 but lower than PCF1 and PCF2 at a wavelength of $1.55 \mu \mathrm{m}$. The nonlinearity value of $40.68 \mathrm{~W}^{-1} \mathrm{~km}^{-1}$ is higher than those reported in ${ }^{5,22,41,54}$. 


\begin{tabular}{|l|l|l|l|l|l|}
\hline $\begin{array}{l}\text { Study } \\
\text { Reference }\end{array}$ & Structure & Nonlinearity $\left[\mathbf{W}^{-\mathbf{1}} \mathbf{k m}^{-\mathbf{1}}\right]$ & Birefringence & Wavelength $[\mu \mathrm{m}]$ & $\begin{array}{l}\text { Dispersion }[\mathbf{p s} / \\
\mathbf{k m} . \mathbf{n m}]\end{array}$ \\
\hline 5 & Circular and elliptical & 39.330 & $2.82 \times 10^{-3}$ & 1.3 & - \\
\hline 41 & All circular & 26.7 & - & 1.3 & +0.6402 \\
\hline 26 & Rhombic and circular & - & $8 \times 10^{-3}$ & 1.55 & - \\
\hline 38 & All Circular & - & $1 \times 10^{-3}$ & 1.55 & $-20,186$ \\
\hline 55 & Square & 23.46 & $2.2 \times 10^{-3}$ & 1.2 & - \\
\hline 54 & All circular & Below 20 & $10^{-2}$ & 1.55 & - \\
\hline 22 & $\begin{array}{l}\text { Circular double cladding } \\
\text { holes }\end{array}$ & 24.48 & $3.11 \times 10^{-2}$ & 1.55 & -513.6 \\
\hline Proposed PCF2 & All circular & 40.68 & $2.02 \times 10^{-2}$ & 1.55 & -47.72 \\
\hline
\end{tabular}

Table 2. Comparison of the proposed PCF with other published works.

The chromatic dispersion for PCF 4 shown in Fig. 4 indicates a curvilinear shape declining towards the longer wavelengths. It has a zero dispersion point at the wavelength of $1.452 \mu \mathrm{m}$. The performance of the proposed structure, PCF4 of ultra high B is compared to other works as shown in Table 2.

Fabrication of proposed PCF. Fabrication of this structure is relatively easy as the number of air hole rings are only four and the air holes used are circular. There are several fabrication options such as extrusion ${ }^{1}$ sol-gel casting ${ }^{2}$ and drilling ${ }^{3}$. The conventional stack and draw technique ${ }^{4}$ has been used to fabricate PCF in ${ }^{5}$ which can also be used for the fabrication of this work. Furthermore, a PCF structure with a relatively smaller air filling fraction of 0.046 has been fabricated ${ }^{6}$, which means that our proposed PCF will be easier to fabricate. The proposed PCF can be fabricated using drilling, or two-step stack and draw method due to the use of circular holes ${ }^{2,3,7,8}$. The sol-gel fabrication method, which offers flexible design freedom with such a lattice structure and is robust against high amounts of bending can also be used for fabricating the proposed structure.

\section{Conclusion}

The numerical analysis of a hexagonal four ring Photonic crystal fiber structure has been presented in this paper. It has been demonstrated that the proposed PCF structure with ultra-high birefringence of $2.02 \times 10^{-2}$, negative chromatic dispersion of $-47.72 \mathrm{ps} / \mathrm{km}$.nm and high nonlinearity of $40.68 \mathrm{~W}^{-1} \mathrm{~km}^{-1}$ at $1.55 \mu \mathrm{m}$ for x-polarisation mode can be achieved. The proposed PCF can be fabricated using a two step stack and draw method or so gel casting method due to its relatively simple structure which consist of circular air holes. This structure with ultra high birefringence, high nonlinearity and negative $\mathrm{CD}$ would be a good candidate for optical fiber communication systems, polarisation maintaining and sensing applications.

Received: 15 September 2020; Accepted: 29 October 2020

Published online: 03 December 2020

\section{References}

1. Thévenaz, L. Advanced fiber optics (EPFL Press, Lausanne, 2011).

2. Saitoh, K. \& Koshiba, M. Leakage loss and group velocity dispersion in air-core photonic bandgap fibers. Opt. Express 11, 3100-3109 (2003).

3. Birks, T. A., Knight, J. C. \& Russell, P. S. J. Endlessly single-mode photonic crystal fiber. Opt. Lett. 22, 961-963 (1997).

4. Akowuah, E. K., Ademgil, H., Haxha, S. \& AbdelMalek, F. An endlessly single-mode photonic crystal fiber with low chromatic dispersion, and bend and rotational insensitivity. J. Lightwave Technol. 27, 3940-3947 (2009).

5. Arif, M. F. H. \& Biddut, M. J. H. A new structure of photonic crystal fiber with high sensitivity, high nonlinearity, high birefringence and low confinement loss for liquid analyte sensing applications. Sens. Bio-Sens. Res. 12, 8-14 (2017).

6. Renversez, G., Kuhlmey, B. \& McPhedran, R. Dispersion management with microstructured optical fibers: ultraflattened chromatic dispersion with low losses. Opt. Lett. 28, 989-991 (2003).

7. Haxha, S. \& Ademgil, H. Novel design of photonic crystal fibres with low confinement losses, nearly zero ultra-flatted chromatic dispersion, negative chromatic dispersion and improved effective mode area. Opt. Commun. 281, 278-286 (2008).

8. Agrawal, G. P. Nonlinear fiber optics: its history and recent progress. JOSA B 28, A1-A10 (2011).

9. Chen, M. \& Xie, S. New nonlinear and dispersion flattened photonic crystal fiber with low confinement loss. Opt. Commun. 281, 2073-2076 (2008)

10. Agrawal, G. Applications of Nonlinear Fiber Optics (Academic Press, New York, 2010).

11. Limpert, J. et al. High-power air-clad large-mode-area photonic crystal fiber laser. Opt. Express 11, 818-823 (2003).

12. Olyaee, S. \& Taghipour, F. Design of new square-lattice photonic crystal fibers for optical communication applications. Int. J. Phys. Sci. 6, 4405-4411 (2011).

13. Latha, G. Solid core photonic crystal fiber for dispersion tailoring in optical tele communication systems

14. Akowuah, E., Ademgil, H. \& Haxha, S. Design and analysis of photonic crystal fibres (PCFs) for broadband applications, in 2012 IEEE 4th International Conference on Adaptive Science \& Technology (ICAST) (2012) 114-120.

15. Ni, Y., Zheng, X. \& Ma, R. Broadband dispersion compensation technology in high speed optical fiber communication systems.

16. Mohammadzadehasl, N. \& Noori M. Design of low-loss and near-zero ultraflattened dispersion PCF for broadband optical communication. Photon. Nanostruct.-Fundam. Appl. 35, 100 (2019).

17. Verma, S. All-circular hole microstructured fiber with high birefringence and low confinement loss. Appl. Opt. 58, 3767-3774 (2019).

18. Suzuki, K., Kubota, H., Kawanishi, S., Tanaka, M. \& Fujita, M. Optical properties of a low-loss polarization-maintaining photonic crystal fiber. Opt. Express 9, 676-680 (2001). 
19. Folkenberg, J. R., Nielsen, M. D., Mortensen, N., Jakobsen, C. \& Simonsen, H. R. Polarization maintaining large mode area photonic crystal fiber. Opt. Express 12, 956-960 (2004).

20. Ademgil, H. \& Haxha, S. Highly birefringent nonlinear PCF for optical sensing of analytes in aqueous solutions. Optik 127, 6653-6660 (2016).

21. Lee, Y. S., Lee, C. G., Jung, Y., Oh, M.-K. \& Kim, S. Highly birefringent and dispersion compensating photonic crystal fiber based on double line defect core. J. Opt. Soc. Korea 20, 567-574 (2016).

22. Lee, Y. S., Hong, S., Kim, S. E. \& Oh, K. Dense double-cladding photonic crystal fiber with high birefringence, large negative dispersion and high nonlinearity, in 2018 23rd Opto-Electronics and Communications Conference (OECC) (2018) 1-2.

23. Paul, B. K. S. Sen, M. Islam, S. Asaduzzaman, S. Chowdhury, M. Hasan, et al., Proposed Square Lattice Photonic Crystal Fiber for Extremely High Nonlinearity, Birefringence and Ultra-High Negative Dispersion Compensation (2017).

24. Saha, R., Hossain, M. M., Rahaman, M. E. \& Mondal, H. S. Design and analysis of high birefringence and nonlinearity with small confinement loss photonic crystal fiber. Front. Optoelectron. 1-9.

25. Faruk, M. M., Khan, N. T. \& Biswas, S. K.Highly nonlinear bored core hexagonal photonic crystal fiber (BC-HPCF) with ultra-high negative dispersion for fiber optic transmission system. Front. Optoelectron. 1-8 (2019).

26. Gao, Y., Sima, C., Cheng, J., Cai, B., Yuan, K., Lian, Z., et al., Highly-birefringent and ultra-wideband low-loss photonic crystal fiber with rhombic and elliptical holes. Opt. Commun. (2019).

27. Habib, M. A., Reza, M. S., Abdulrazak, L. F. \& Anower, M. S. Extremely high birefringent and low loss microstructure optical waveguide: design and analysis. Opt. Commun. 446, 93-99 (2019).

28. Hasan, M. R., Islam, M. A., Rifat, A. A. \& Hasan, M. I. A single-mode highly birefringent dispersion-compensating photonic crystal fiber using hybrid cladding. J. Mod. Opt. 64, 218-225 (2017).

29. Kumar, P., Fiaboe, K. F. \& Roy, J. S. Highly birefringent do-octagonal photonic crystal fibers with ultra flattened zero dispersion for supercontinuum generation. J. Microw. Optoelectron. Electromagn. Appl. 18, 80-95 (2019).

30. Wang, J., Jiang, C., Hu, W. \& Gao, M. High birefringence photonic bandgap fiber with elliptical air holes. Opt. Fiber Technol. 12, 265-267 (2006).

31. Hasan, M. R., Anower, M. S. \& Hasan, M. I. Polarization maintaining highly nonlinear photonic crystal fiber with closely lying two zero dispersion wavelengths. Opt. Eng. 55, 056107 (2016).

32. Ghunawat, A. K., Chandra, R., Tiwari, M. \& Singh, G. Design optimization of a highly birefringent and highly nonlinear silicon photonic crystal fiber," in Optical and Wireless Technologies. Springer (2018) 301-308.

33. Prajapati, Y., Srivastava, V., Singh, V. \& Saini, J. Effect of germanium doping on the performance of silica based photonic crystal fiber. Optik 155, 149-156 (2018).

34. Liu, Q., Liu, Q., Sun, Y., Liu, W., Liu, C., Li, Q., et al. A high-birefringent photonic quasi-crystal fiber with two elliptical air holes. Optik (2019).

35. Ahmed, F., Kumar, P., Hakim, M. A., Miah, M. S., Al Noman, A. \& Biswas, S. K. Ultrahigh birefringence and highly nonlinear square photonic crystal fiber for S+ C+ L+ U wavebands, in 2018 9th International Conference on Computing, Communication and Networking Technologies (ICCCNT) (2018) 1-4.

36. Soni, A., Kumar, P. \& Roy, J. S. Ultra low loss photonic crystal fiber with high birefringence, in 2017 2nd International Conference on Communication and Electronics Systems (ICCES) (2017) 383-385.

37. Yang, T., Wang, E., Jiang, H., Hu, Z. \& Xie, K. High birefringence photonic crystal fiber with high nonlinearity and low confinement loss. Opt. Express 23, 8329-8337 (2015).

38. Lee, Y. S., Lee, C. G., Bahloul, F., Kim, S. \& Oh, K. Simultaneously achieving a large negative dispersion and a high birefringence over $\mathrm{Er}$ and Tm dual gain bands in a square lattice photonic crystal fiber. J. Lightwave Technol. 37, 1254-1263 (2019).

39. Biswas, S. K., Arfin, R., Habib, A. B., Amir, S. B., Zahir, Z. B., Islam, M. R., et al. A modified design of a hexagonal circular photonic crystal fiber with large negative dispersion properties and ultrahigh birefringence for optical broadband communication, in Photonics (2019) 19.

40. Halder, A. \& Hossain, S. A. Design of ultra-high birefringent broadband dispersion compensating photonic crystal fiber for high speed transmission system. Imperial J. Interdisc. Res 2, 211 (2016).

41. Chauhan, P., Kumar, A. \& Kalra, Y. A dispersion engineered silica-based photonic crystal fiber for supercontinuum generation in near-infrared wavelength region. Optik 187, 230-237 (2019).

42. Talukder, H., Isti, M. I. A., Nuzhat, S. \& Biswas, S. K. Ultra-high negative dispersion based single mode highly nonlinear bored core photonic crystal fiber (HNL-BCPCF): design and numerical analysis. Braz. J. Phys. 1-9 (2020).

43. Bjarklev, A., Broeng, J. \& Bjarklev, A. S. Photonic Crystal Fibres (Springer, New York, 2012).

44. Saitoh, K., Koshiba, M., Hasegawa, T. \& Sasaoka, E. Chromatic dispersion control in photonic crystal fibers: application to ultraflattened dispersion. Opt. Express 11, 843-852 (2003).

45. Ortigosa-Blanch, A. et al. Highly birefringent photonic crystal fibers. Opt. Lett. 25, 1325-1327 (2000).

46. Kim, S. E. et al. Elliptical defected core photonic crystal fiber with high birefringence and negative flattened dispersion. Opt. Express 20, 1385-1391 (2012).

47. Beltrán-Mejía, F. et al. Ultrahigh-birefringent squeezed lattice photonic crystal fiber with rotated elliptical air holes. Opt. Lett. 35, 544-546 (2010).

48. Islam, M. I. et al. Proposed square lattice photonic crystal fiber for extremely high nonlinearity, birefringence and ultra-high negative dispersion compensation. J. Opt. Commun. 40, 401-410 (2019).

49. Yang, T.-J. et al. High birefringence and low loss circular air-holes photonic crystal fiber using complex unit cells in cladding. Opt. Commun. 281, 4334-4338 (2008).

50. Sonne, A. \& Ouchar, A. Improving of high birefringence photonic crystal fiber with low confinement loss using small elliptical air holes in the core region. J. Mod. Opt. 62, 588-592 (2015).

51. Bouk, A., Cucinotta, A., Poli, F. \& Selleri, S. Dispersion properties of square-lattice photonic crystal fibers. Opt. Express 12, 941-946 (2004).

52. Monfared, Y. E. \& Ponomarenko, S. A. Extremely nonlinear carbon-disulfide-filled photonic crystal fiber with controllable dispersion. Opt. Mater. 88, 406-411 (2019).

53. Gangwar, R. K. \& Singh, V. K. Study of highly birefringence dispersion shifted photonic crystal fiber with asymmetrical cladding. Optik 127, 11854-11859 (2016).

54. Gautam, A., Mahato, D. \& Kumar, P. Design of photonic crystal fibers for high data rate transfer at ultra low confinement loss. International Conference on Communication and Signal Processing (ICCSP) 2018, 0354-0357 (2018).

55. Ahmed, K. et al. Ultra high birefringence and lower beat length for square shape PCF: Analysis effect on rotation angle and eccentricity. Alex. Eng. J. 57, 3683-3691 (2018).

56. Kiang, K. et al. Extruded singlemode non-silica glass holey optical fibres. Electron. Lett. 38, 546-547 (2002).

57. Couny, F., Roberts, P. J., Birks, T. \& Benabid, F. Square-lattice large-pitch hollow-core photonic crystal fiber. Opt. Express 16, 20626-20636 (2008).

58. Buczynski, R. Photonic crystal fibers. Acta Physica Polonica Ser. A 106, 141-168 (2004).

59. Valentin, C. et al. Top-hat beam output of a single-mode microstructured optical fiber: Impact of core index depression. Opt. Express 21, 23250-23260 (2013). 
60. Buczynski, R., Szarniak, P., Pysz, D., Kujawa, I., Stepien, R. \& Szoplik, T. Double-core photonic crystal fiber with square lattice, in Photonic Crystal Materials and Nanostructures (2004) 223-230.

61. Falkenstein, P., Merritt, C. D. \& Justus, B. L. Fused preforms for the fabrication of photonic crystal fibers. Opt. Lett. 29, 1858-1860 (2004).

\section{Acknowledgements}

The authors would like to thank Prof. K.O. Boateng for his support and guidance as well as Dr. Selorm Klogo and Dr. Henry Nunoo Mensah for their support.

\section{Author contributions}

Written by P.A.A. and supervised by E.K.A.

\section{Competing interests}

The authors declare no competing interests.

\section{Additional information}

Correspondence and requests for materials should be addressed to P.A.A.

Reprints and permissions information is available at www.nature.com/reprints.

Publisher's note Springer Nature remains neutral with regard to jurisdictional claims in published maps and institutional affiliations.

(c) (i) Open Access This article is licensed under a Creative Commons Attribution 4.0 International

License, which permits use, sharing, adaptation, distribution and reproduction in any medium or format, as long as you give appropriate credit to the original author(s) and the source, provide a link to the Creative Commons licence, and indicate if changes were made. The images or other third party material in this article are included in the article's Creative Commons licence, unless indicated otherwise in a credit line to the material. If material is not included in the article's Creative Commons licence and your intended use is not permitted by statutory regulation or exceeds the permitted use, you will need to obtain permission directly from the copyright holder. To view a copy of this licence, visit http://creativecommons.org/licenses/by/4.0/.

(C) The Author(s) 2020, corrected publication 2021 